\title{
Inside GNSS: An open source SDR receiver for GPS users
}

\author{
bilal beldjilali ${ }^{1}$
}

${ }^{1}$ Affiliation not available

May 5, 2020

\begin{abstract}
Navigation based satellite system, in the image of GPS system, occupy a crucial place in our daily activities: finding its way, a place or tracking a craft.... The increasingly prevalent applications of such systems are driving the development of increasingly sophisticated GPS receivers. This research work falls within this perspective and aims at the development and design of algorithms for future generations of satellite location receivers based SDR technology. The proposed approach for this research work is based on the satellite collection signal in RAW format and their digital processing, all by improving and elaborating localization algorithms. The work presented aim to design and integrate a system able of processing the signals recorded in RAW format on a CPU unit based on correlation, FFT, PLL and DLL modules. Different algorithms and advanced signal processing techniques are implemented and validated. The work carried out aims at identifying, modeling and correcting the errors introduced on the signals initially emitted by the satellites as the Ionospheric and Tropospheric errors, the supreme objectives relate to the design of a real-time GPS receiver.
\end{abstract}

\section{Hosted file}

wileyNJD-AMA.pdf available at https://authorea.com/users/296095/articles/424943-inside-gnssan-open-source-sdr-receiver-for-gps-users 